\title{
Avaliação Das Boas Práticas de Fabricação em Uma Panificadora do Município de Limoeiro do Norte-CE
}

\author{
Monique de Oliveira Maia (I), Mônica de Oliveira Maia (I), Daniele \\ Maria Alves Teixeira Sá (I), Monique Ellen Torres da Silva (I), \\ Marlene Nunes Damaceno (I), Virna Luiza de Farias (I), Renata \\ Chastinet Braga (I), Herculana Carvalho Castro (I), Antônio Antônio \\ Belfort Dantas Cavalcante (I) \\ (I) IFCE - Instituto Federal do Ceará (Rua Estevão Remígio, 1145, Centro, 62930-000, Limoeiro \\ do Norte, Ceara, Brasil.)
}

\section{Resumo}

A implementação das Boas Práticas de Fabricação (BPF) em um estabelecimento do ramo alimentício é indispensável para o oferecimento de produtos de boa qualidade higiênico-sanitária aos seus comensais. Neste sentido, o presente estudo teve como objetivo avaliar as BPF em uma panificadora do município de Limoeiro do Norte-CE. Para a avaliação das BPF foi utilizado um check-list embasado na Resolução RDC N² 216/04, o qual constou de 88 itens de observação, distribuídos em vários aspectos do estabelecimento, como edificação e instalações (estrutura e higienização); abastecimento de água; manejo de resíduos; controle integrado de vetores e pragas urbanas; manipuladores; matérias-primas, ingredientes e embalagens; preparação do alimento; exposição ao consumo; documentação e registro e responsabilidade. As opções de resposta para o preenchimento do check-list foram: "Conforme" $(\mathrm{C})$ - quando a panificadora atendeu o item especificado e "Não Conforme" (NC) quando o estabelecimento apresentou não conformidade para o item observado. Os resultados foram analisados de acordo com o percentual de conformidade segundo a legislação vigente utilizando-se o programa Excel ${ }^{\circledR}$ 2010. Durante a visita à panificadora, o check-list foi preenchido através de observações no próprio local e informações fornecidas pelo

\footnotetext{
Referência:

Monique de Oliveira Maia, Mônica de Oliveira Maia, Daniele Maria Alves Teixeira Sá, Monique Ellen Torres da Silva, Marlene Nunes Damaceno, Virna Luiza de Farias, Renata Chastinet Braga, Herculana Carvalho Castro, Antônio Antônio Belfort Dantas Cavalcante. Avaliação Das Boas Práticas de Fabricação em Uma Panificadora do Município de Limoeiro do Norte-Ce. In: Anais do 12 Congresso Latinoamericano de Microbiologia e Higiene de Alimentos MICROAL 2014 [= Blucher Food Science Proceedings, num.1, vol.1]. São Paulo: Editora Blucher, 2014. DOI 10.5151/foodsci-microal-210
} 
proprietário do estabelecimento. Verificou-se, no presente estudo, um baixo percentual de conformidade para todos os itens avaliados, sobretudo para o item documentação e registro, para o qual observou-se ausência de conformidade, uma vez que a panificadora visitada não possuía Manual de Boas Práticas de Fabricação (MBP) e Procedimentos Operacionais Padronizados (POP). A partir deste estudo foi possível inferir que a panificadora avaliada não estava em conformidade com a legislação sanitária vigente, o que contribui para o aumento do risco de ocorrência de doenças transmitidas por alimentos. Concluiu-se, portanto, que a atuação da fiscalização sanitária nos serviços de alimentação deveria ser mais efetiva, a fim de minimizar os riscos de contaminação e, desta forma, preservar a saúde dos consumidores.

Palavras-Chave: Boas Práticas, controle de qualidade, legislação, segurança alimentar

Agência de Fomento: Capes e Funcap 